\title{
AIAA $91-3650$
}

Some Physics Issues Facing the Open-Cycle Gas Core Nuclear Rocket

T. Kammash and D. Galbraith

The University of Michigan Ann Arbor, Ml

\section{AIAA/NASA/OAI Conference on Advanced SEI Technologies} September 4-6, 1991 / Cleveland, $\mathrm{OH}$ 


\title{
SOME PHYSICS ISSUES FACING THE OPEN CYCLE GAS CORE NUCLEAR ROCKET
}

\author{
T. Kamrash and D. L. Galbralth \\ Department of Nuclear Engineering \\ The University of Nichlgan \\ Ann Arbor, MI 48109
}

\begin{abstract}
The Open Cycle Gas Core Nuclear Rocket (GCR) offers attractive propulsion characteristics that might allow round trip missions to Mars to be undertaken in reasonably short times. In this scheme, the heat generated by a fissioning uranlum plasma core heats, through radiation. a hydrogen propellant which, when exhausted through a nozzle, converts thermal energy Into thrust. This type of confinement is, however, subject to hydrodynamic Instabilities which could result in the loss of a significant portion of the fuel in a relatively short time. Moreover, acoustle instabllities arising from density and temperature fluctuations could result in serious control problems for GCR. In this paper, we address the underlying physics of these phenomena and estimate the Lopact they may have on travel times to Mars.
\end{abstract}

\section{Introduction}

The Space Exploration Initiative calls for, among other things, a manned.mission to the planet Mars sometlme in the early part of the next century. Since space travel is hazardous and man is unable to endure long journeys without experiencing physical and mental degradation, it is imperative that such missions be completed in the shortest possible time. This in turn means that one or more "advanced" rocket propulsion schemes must be developed to meet these objectives. One promising approach in this regard is the open cycle gas core (1) fission reactor (GCR). The principle of operation in GCR involves a critical uranium core in the form of a gaseous plasma that heats, through radlation, a hydrogen propellant which exits through a nozzle, thereby converting thermal energy into thrust as demonstrated In Fig. 1.

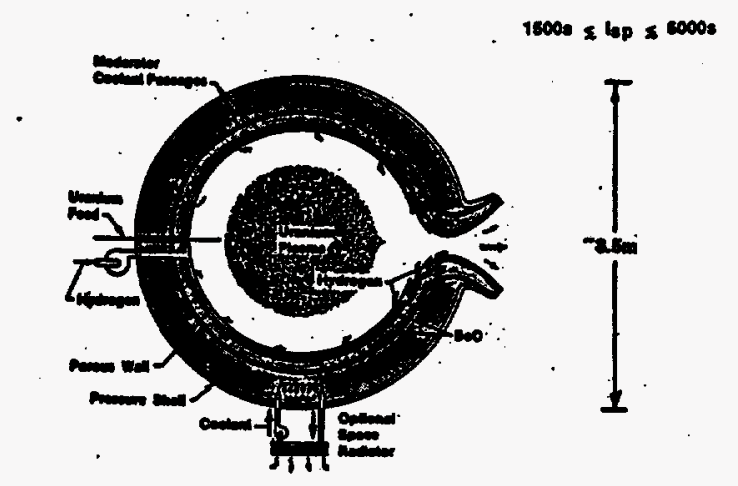

Fo. 1.

Migh Specilic Imputee, Porous What cas Core Engine. (Courtery of MASA, Lemis Pevearch Conter)
The temperature limitations imposed by material melting as encountered in rolld core thermal rocket designs is avoided in GCR since the nuclear fuel is allowed to exist in a high temperature $\left(10.000-100.000^{\circ} K\right)$ partially ionized state. In this so-called "gaseous - or plasma core" concept, the sphere of fissioning uranium plasma tunctlons as the fuel element of the reactor. Nuclear heat released within the plasma and dissipated as thermal radiation from the surface is absorbed by a surrounding envelope of seeded hydrogen propellant which is then expanded through a nozzle to generate thrust. Propellant seeding with small amounts of graphlte or tungsten powder Is necessary to insure that the thermal radiation is absorbed primarily by the hydrogen and not by the cavity walls that surround the plasma. With the gas core rocket concept, specific impulse values ranging from $: 500$ to 7000 seconds appear to be feasibleit). As shown In Fig. 1, the open cycle CCR Is basically spherical in shape and contains three solld regions: an outer pressure vessel, a neutron reflector/moderator, and an Inner porous liner. Because of its high operating temperature and its compatlbllity with hydrogen, beryllium oxide is usually selected for the moderator material. This reactor concept requires a relatively high pressure plasma $(600-2000$ atm) to achieve a critical mass. At these pressures, the gaseous fuel is sufficiently dense for the fission fragment stopping distance (average distance travelled for energy deposition) to be comparable to or smaller than the dimensions of the fuel volume contained within the reactor cavity. The hydrogen propellant Is injected through the porous wall with a flow distribution that creates a relatively stagnant, non-recirculating central fuel region in the cavity. It has been suggested(z) that a small amount of fisslonable fuel (up to $1 \%$ of the hydrogen mass flow rate) gets exhausted along with the heated propellant under normal conditions. It is also noted that, due to the transparency of both the uranium plasma and the hot hydrogen, $7-\mathbf{1 0} \%$ of the total reactor power appears as radiation whlch is ultimately deposited principally in the solid regions of the reactor wall. It is the ability to remove thls energy. either by means of an external radiator or regeneratively using the hydrogen propellant, that determines the maximum power output and achievable specific impulse for GCR engines.

\section{Some Physics Issues in GCR}

To highlight some of the major physics and engineering issues which this propulsion approach must overcome, we choose a preliminary design for which the relevant parameters are available. We Identlty a reactor des!gn(3) In which the radius of the uranium core, $R$, is $\mathbf{1}$ meter; the pressure in the system Is $\mathbf{1 0 0 0}$ atm; and the hydrogen temperature is about $17,500^{\circ} \mathrm{K}$, which suggests that the fuel temperature is about $35.000^{\circ} K(4)$. Our elementary analysis of this $7500 \mathrm{MW}$ system shows that the mean velocity of the hydrogen, which is 
commensurate wlth a cited mass flow rate of $4.6 \mathrm{Kg} / \mathrm{sec}$, is approximately $6 \mathrm{~m} / \mathrm{sec}$. The mean velocity of the uranium in the core is generally taken to be 10 - 16 times smaller than that of the propellani(b). As a result, it can be safely assumed to be stationary in the analysis of the relative motlon of $\imath$ wo superposed fluids.

It is a knon fact that wen a fluid of density $\boldsymbol{\rho}_{2}$ moves wlth veloclty $\boldsymbol{v}_{2}$ past another fluid of density $\rho_{1}$ which is stationary. in the presence of a gravitatlonai force, the (sharp) boundary between them will, upon perturbation, undergo oscillations whlch under certain conditions can become unstable. This Instabllity, known as the Kelvin-Helmholtz Instability'ss, can lead to turbulent diffusion of materlal from one region into the other, and, ln the case of GCR. this could mean substantial flow of uranium from the core lnto the hydrogen and thus out through the nozzle. Not only wlll the loss of uranlum affect the criticality of the system is not replaced appropriately, but also the flow of hydrogen lnto the core wlll affect its composition and ultirnately its criticality.

To assess the importance of thls phenomenon, we apply it to the GCR design noted above. We recall that in that example the mean veloclty of the hydrogen is about $5 \mathrm{~m} / \mathrm{sec}$, with the uranium in the core treated as immobile. As a result, the system can be vlewed as consisting of a fluid (H) of density $\boldsymbol{\rho}_{\mathbf{2}}$ and velocity $\boldsymbol{v}_{\mathbf{2}}$, movlng past a statlonary Iuid (U) of density $\rho$, under the influence of a gravitational acceleration $\theta$. In thls case, the instabilltv condltlon can be wrltten $\mathbf{a s}(\mathbf{2 0})$

$$
v_{2}^{2}>\frac{g\left(p_{1}^{2}-p_{2}^{2}\right)}{p_{1} p_{2}} \cdot \frac{g p_{1}}{k} p_{2}
$$

where we have taken advantage of the fact that, for the pressure and temperature under consideration, the uranium density is much larger than that of hydrogen. The above equation reveals that the mlnlmum wave number $\boldsymbol{k}$ of the osclliatlon is

$$
k_{=12}=\frac{g p_{1}}{v 2 p_{2}}
$$

while the corresponding growth rate $\gamma$ of the lnstabllity can be put in the form

$$
Y_{\text {a1 }}=v_{2} k_{m+1} \sqrt{\frac{p_{2}}{p_{1}}}=\frac{g}{v_{2}} \sqrt{\frac{p_{1}}{p_{2}}}
$$

The diffusion coefflclent Dfor the uranium flow lnto the hydrogen can be approximately expressed by

$$
D-\frac{y}{k^{2}}
$$

from which we can wrlte the particle flux as

$$
\boldsymbol{F}=\frac{D p_{1}}{R}
$$

where $\mathrm{Ris}$ the radius of the spherical uranlum core mentioned earlier. The amount of uranium escaping per second by thls diffusion process, $U_{6}$, can finally be wrltten as

$$
U_{L}=4 \pi R^{2} F=4 \pi R D_{P_{1}}
$$

or, as a fraction of the total uranlum $U_{s}$ present in the sphere.

$$
\frac{U_{L}}{U_{3}}=\frac{4 \pi R D p_{1}}{\frac{6}{3} \pi R^{3} p_{1}}=\frac{3 D}{R^{2}}=\frac{3 Y}{R^{2} k^{2}}
$$

At a pressure of $1000 \mathrm{~atm}$, a hydrogen temperature of 17.500' $\mathrm{K}$, and a uranium temperature of $35,000^{\prime} \mathrm{K}$, the densities of hydrogen and uranium are, respectively, $4.64 \times 10^{-4} \mathrm{gm} / \mathrm{cm} \mathrm{m}^{7}$ and $5.53 \times 10^{-2} \mathrm{gm} / \mathrm{cm}^{3}$. Wlth these values, and $\boldsymbol{v}_{2}=\mathrm{E} \mathrm{m} / \mathrm{sec}$, Eqn. 6 yields about $7 \mathrm{Kg} / \mathrm{sec}$ uranium loss, while Eqn. 7 shows that approximately 3\% of the fuel escapes per second. Clearly, these quantltles are unacceptably large, and well over the $1 \%$ of the hydrogen mass flow rate (1,e, $45 \mathrm{gm} / \mathrm{sec}$ ) often cited as the loss due to turbulent mixing. In additlon, this loss is far greater than the Uranium burnup rate $(0.1 \mathrm{gm} / \mathrm{sec}$ of U235), As can be seen from Eqn. 3, the growth rate for a 1 sed wave number (1.e. a flxed wave length) le smaller for smaller hydrogen flow velocity. But decreasing thls velocity beyond a certain value may not be compatible wlth the mass flow rate dictated by heat transfer needs. The synergetles of problems dealing wlth turbulent mising and concomitant loss of uranium, criticality requlrements and associated fueling, and heat transfer requirements. not only of the propellant but components subjected to hlgh heat loads, may prove to be a formidable problem lndeed for the gas core reactor.

In obtainlng the above results, we had employed mean temperature and velocity values for the propellant and the fuel. In reality, however, the density, temperature, and velocity of the propellant possess radlal gradients whlch play a major role in stablllty considerations. Noting that the ratlo of the buoyancy force to the irerta is given by the Richardson number $\mathcal{J}$, where

$$
J=-\frac{g}{P I !} \frac{d p_{2} / \partial z}{\left(\partial v_{2} / \partial z\right)^{2}}
$$

it can be shown[uo that $J>\frac{1}{4}$ leads to stablllzation of the Kelvin-Helmholtz instability. It is clear from the above expression that an "inverted" propellant denslty profile. wlth the denser layer belng adjacent to the fuel, is required for stablllty. This is diffleult to achieve since the hotter (and hence less dense) region is adjacent to the fuel. Unless some means can be found (such as using a buffer layer) to generate the desired profile, this instability and the resultlng turbulent mlxlng wlll always persist in the Gas Core reactor.

If proflling' effects cannot be achieved or sustalned. then perhaps the use of magnetic Melds to suppress thls lnstabllity may not be totally avolded. It has been shown'10) that if a magnetic fleld $B$ is Introduced in the dlrectlon of the propellant flow, then 1 t can act as a "surface tension' type of force that provides stability if the followlng condltion is satlsfled:

$$
\frac{p_{1} p_{2}}{\left(p_{1}+p_{2}\right)} v_{2}^{2} \leq \frac{B^{2}}{8 \pi}
$$

We see that, for the case at hand, a minimum magnetic fleld strength of about 64 Gauss is required. The shape of such a fleld is likely to be "mirror" - like in order to accommodate the flow around the spherlesl uranlum core. Although such a fleld can bring about stabilization of the Kelvln-Helmholtz lnstabillty, it is much too small to contine a uranium plasma at $\mathbf{1 0 0 0}$ atmospheres pressure, but might be adequate to respond to pressure fluctuations that may occur in the system.

The problem of uranium loss due to turbulent mixing is closely linked to that of fueling, since the latter must also take into account the loss due to 
burnup. We propose "pellet" fueling to compensate for these losses! This approach has the potential of injecting fuel into the hottest region of the core, where it can readily vaporize and ionize, with the aded advantage of minimslly disturbing the homogeneity of the uranium plasma core. Moreover, this method could also be utilized in the presence of magnetic flelds $\left.{ }^{7}\right)$ should uranium confinement by such fields prove feasible and desirable.

To get an idea of how fast suitably chosen uranium pellets must be injected into a spherical uranium core, we use the parameters of the reactor design alluded to earlier. namely $R=1 \mathbf{m}$, $T_{H}=17,500^{\circ} \mathrm{K}, T_{v}=35,000^{\circ} \mathrm{K}, P=1000$ atm. Noting that the ionization potential " $\varepsilon$ " of uranium is 6.18 ev(s), we can estimate the pellet ablation time $t_{1}$ fram

$$
t_{1}=\frac{r_{, n, \epsilon}}{q_{1}}
$$

where $r$, is the radius of the injected pellet, $r_{\text {, }}$ is the solid state density. and $q$. Is the heat flux which, in the case of a uranium plasma, Is associated primarily with the electrons. At a fuel temperature of $35,000^{\circ} \mathrm{K}$,

9. $-6.2 \times 10^{28} \mathrm{eV} / \mathrm{cm}^{2}-$ sec, and for a pellet radius of $6 \mathrm{~cm}$, the ablation time is $1.5 \times 10^{-5} \mathrm{sec}$.

The velocity with whlch this pellet must be injected, to reach the center of the core before being totally ionized. is $v_{m,}=R / t_{1}$, and for

$R=1 \mathrm{~m}$, it has the value of about $87 \mathrm{~km} / \mathrm{sec}$. This is a very high speed. and is perhaps out of reach for current or near term technology. But this number should not be taken serlously, since a "bare" pellet does not remain bare once it enters the hot uranium core. In fact, It can be shown that a "neutral' shield forms around the pellet when it enters the core, and this shield drastically reduces the heat flux impinging on the pellet, thereby greatly increasing the ablation lifetime. It has been shown(i) that a reduction of $10^{4}$ in the required Injection velocity may result from the presence of the shield and, for the case at hand, the injection velocity reduces to $6.7 \mathrm{~m} / \mathrm{sec}$, which is well within the technology capabillty.

With $6 \mathrm{~cm}$ radius pellets of uranium, less than one pellet per second is required to make up the turbulent mixing loss. However, such a pellet is relatively massive, and may seriously distort the fuel distribution in the reactor until it ablates and is redistributed. In addition, while the injection velocity for such a pellet is relatively small, accelerating such a masslve object to this speed requires a greater acceleration force than would be required to give a smaller pellet a much greater speed. Table I shows the trade-offs between pellet size, injection rate, injection velocity $V_{i n)}$, and the force $F_{\text {in, }}$ required to achieve this velocity assuming that the injector accelerates the pellet unlformly over a distance of one meter.

As an indication of how seriously turbulent mixing can affect the propulsive performance of the Gas Core Reactor, we have calculated the round trip time, $\boldsymbol{\tau}_{\boldsymbol{e}}$, to Mars for various ratios of uranlum mass flow rate to hydrogen mass flow rate using the dry vehicle mass of $123^{\prime}$ MTgiven in the design
TABLE I

Injection Parameters for Various CCR Pellet Sizes

\begin{tabular}{|c|c|c|c|c|}
\hline $\begin{array}{l}\text { Radius } \\
r(\mathrm{~cm})\end{array}$ & $\begin{array}{c}\text { Mass } \\
\boldsymbol{M}, \\
\langle\boldsymbol{g}\rangle\end{array}$ & $\begin{array}{c}\text { Injection } \\
\text { Rate } \\
\left\langle s \otimes c^{-1}\right\rangle\end{array}$ & $\begin{array}{c}V_{\text {int }} \\
(m / s \otimes c)\end{array}$ & $\begin{array}{c}F_{(\mathbf{n})} \\
\text { (dynes) }\end{array}$ \\
\hline $\begin{array}{l}0.6 \\
1 . \\
2 . \\
6 .\end{array}$ & & & $\begin{array}{l}66.882 \\
33.441 \\
16.721 \\
6.6882\end{array}$ & $\begin{array}{l}6 \times 10^{\circ} \\
2 \times 10^{6} \\
43106 \\
6 \times 10^{9}\end{array}$ \\
\hline
\end{tabular}

cited earlier. Noting that the thrust, $\boldsymbol{F}$. and the speclele impulse, $l, s$, can be written as

$$
\begin{aligned}
& F=\sum \dot{m}_{i} v_{1} \\
& t_{t p}=\frac{F}{g \sum_{j} m_{1}}
\end{aligned}
$$

where $\boldsymbol{g}$ is the gravitational acceleration, and the round trip time $\tau_{\lambda,}$ as

$$
\tau_{k T}=\frac{4 D}{g l_{s p}}+4 \sqrt{\frac{D m_{f}}{F}}
$$

where $D$ is the one way distance and $m$, is the dry mass, we obtain the results shown in Table II for a propellant temperature of $17.500^{\prime} \mathrm{K}$ and uranium temperature of $35,000^{\circ} \mathrm{K}$.

TABLE II

Effects of Turbulent Mixing

\begin{tabular}{lrrrrr}
$\dot{m}_{U} / \dot{m}_{H}$ & $F(K N)$ & & $I_{s p}(\mathrm{sec}) \tau_{R T}$ (days) \\
\cline { 1 - 2 } \cline { 5 - 5 } 0 & 87.6 & & 1987 & 197 \\
0.01 & 87.7 & & 1970 & 198 \\
0.1 & 88.6 & & 1820 & 213 \\
0.5 & 92.2 & & 1390 & 280 \\
1.0 & 96.8 & & 1098 & 344 \\
2.0 & 106.02 & & 940 & 398
\end{tabular}

Another problem of major concern in CCR has to do with acoustic instabilltles that might arise as a result of fluctuations in the density and temperature of the fissioning uranium plasma. The mechanism for the generation of such oscillations can be described as follows(10): We imagine a standing sound wave to exist in a bounded region of a tisslonin\& plasma that includes a constant background density of thermal neutrons. In the wave compressions, the fission power density increases due to the increased uranlum denslty, whlle in the rarefactions the power decreases. This results in an increased pressure gradient associated with the wave, which in turn leads to a transfer of Ilssion power to the wave. It occurs because the dense portion of the wave tends to expand faster than it was compressed. But competing with this is the fact that radiation also tends to transport the extra thermal energy out of the wave compressions. Moreover, radiation diffusion tends to smooth out the temperature fluctuations of waves more rapidly as their wavelengths become shorter. This results in a critical wavelength below which waves are stable and above which they are unstable. If the characteristic dimension of the system, such as the core radius, is larger than this critical wavelength, then the system $\mathbb{1}$ I! be subject to these instabilltles, which could precipitate significant pressure 
fluctuations and thus present serious control problems for thls englne. In addition, such unstable waves could also glve rise to a slgnlflcant uranium loss from the core; thls fuel would $\mathrm{mlx}$ wlth the propellant then exiting through the nozzle.

It can be shown $\pi^{(10)}$, wlth the id of standard fluld equations for the uranlum plasma, that if the charge state of the uranium lon (assumed here to be singly lonized) does not change during thls phenomenon, then the llnear growth rate of the acoustic lnstablllty can be written as(10)

$$
Y=\frac{\left\{2 P_{,} / M-k^{2} K_{a}\left[V^{2}-2 K T_{0} / M\right] / K\right\}}{6 N_{0} V^{2}}
$$

where the sound speed. $V_{t}$, Is glven by

$$
\text { V. }-\left(\frac{10}{3} \frac{K T_{0}}{M}\right)^{1 / 2}
$$

and $\boldsymbol{P}_{,}, N_{0}$, and $T_{0}$ are respectively the flssion power density. uranium density, and uranlum temperature. The uranium mass is glven by $M$, the Boitzmann Constant by $\mathcal{K}$, the wave number of the osclllatlon by $k$, and the radlatlon dlffuslon coefllelent by $\mathrm{K}$, which is deflned as

$$
K_{2}=\frac{160, T^{3}}{3} \frac{k_{2}}{k_{2}}
$$

wlth $\sigma_{2}$ belng the black body constant and $k$, the mean Rosseland opacity coefflclent, he note from Eqn. 12 that a positive numerator glves rise to an lnstablllty (1.e. a wave wlth growing amplitude) while a negative value denotes a damped wave. The transition from one to the other is characterlzed by a crltlcal wave number $k_{\epsilon}$ glven by

$$
k_{c}=\left[\frac{5 K P_{F}}{M V^{2} K_{l}}\right]^{1 / 2}=\left[\frac{3}{2} \frac{P_{F}}{T_{0} K_{A}}\right]^{1 / 2}
$$

which. upor substltutlon in Eqn. 12, yields

$$
y=\frac{K_{2}}{15 K N_{0}}\left\{k_{c}^{2}-k^{2}\right\}
$$

For the reactor example presented earlier. the above equation becomes

$$
y=3.7 \times 10^{2}\left\{k_{c}^{2}-k^{2}\right\}
$$

and upon lnsertlng the appropriate parameters we find that the crltlcal wave number value is $\boldsymbol{t}_{6} \cdot \mathbf{0 . 0 8 4}$ and the crltlcal wavelength is $\lambda_{c} \cdot 75 \mathrm{~cm}$. Since the radlus of the core is $1 \mathrm{~m}$, it is clear that such a system will support acoustic lnstabllitles, and for wave numbers corresponding to thls dlmenslon, Eqn. 17 shows that the e-foldlng time is about 0.9 seconds. Although detalled non-llnear analysls is required to assess the impact of these lnstabllitles, one can estlmate the loss of fuel from the core due to these oscillations by using Eqns. 6 and 7 along wlth 16. One flnds, for the case at hand, that about $9 \%$ of the uranlum plasma per second wlll be transported out of the core, which corresponds to a fuel mass flow rate of about $20 \mathbf{k g} / \mathbf{s e c}$. Assuming that such losses can be replenlshed by appropriate refueling schemes, one can also see, from an extension of Table II to include thls case, that such a uranium mass flow rate wlll result in a round telp to Mars of about 600 days.

\section{Conclusion}

We have examlned brlefly in thls paper several physics phenomena that mlght have adverse effects on the vlablllty of the open cycle gas core rocket as a potentlal propulsion scheme for the space exploration lnltlatlve. The flrst has to do wlth vortex conflnement of the fuel, which renders it unstable to hydrodynamic lnstabllitles of the Kelvln - Helmholtz type, and the other has to do wlth acoustlc lnstabllitles arlslng from density and temperature fluctuations. In both cases. substsntial amounts of uranium may be transported out of the core and expelled through the nozzle, wlth the unwelcome result of slgnlficantly reduetng the speclflc impulse and lncreaslng the travel time. These phenomena also present serious challenges concerning the fuellng of the reactor to malntain crltlcallty, and general dynamics and control problems for such an englne. Finally, it mlght be noted that the Light Bulb concept(14) which employs a barrier to separate the fuel from the propellant may not experlence a Kelvln-Helmholtz lnstablllty that ejects uranlum from the core, but it is more llkely to experlence the acoustic lnstabllity since the barrier is bound to impede the escape of radlatlon from the core.

\section{References}

1. R. G. Ragsdale, Nuclear Thermal Propulslon A Jolnt NASA/DOE/DOD Workshop, Cleveland, OH, July 10-12 (1990)

2. R. G. Ragsdale and E. A. W1111s, Jr., AIAA Paper 71-641,

7 th Propulslon Jolnt Speclalist Conference, Salt Lake City, Utah, June 14-18 (1971)

3. S. K. Borowskl, NASA Technical Memorandum 101364, Juiy $18(1987)$

4. A. F. Kascak and A. J. Easley, NASA TN D-4882, August 6 (1968)

6. R. E. Hyiand. R. G. Ragsdale, and E. J. Gunn, NASA TN D-1676, March (1963)

c. S. Cnandrasekhar, Hydrodynamle and Hydromannetlc stablity, Dover Publications N.Y. (1961)

7. G. Zavala and T. Kammash, Fuslon Technology $\underline{\mathbf{6}}, 30$ (1984)

8. M. Benedlct, T. Plgford, and H. Levl, Nuclear Chemical Ennlneerlng, NoGraw Hlll, N.Y. (1981)

9. C. Chang et. al., Nuclear Fuslon 20, 869 (1980)

10. D. A. Tidman, 2nd Sympostum on Uranlum Plasmas: Research A Appllcatlons Atlanta, Nov. 16-17 (1971) p. 99

11. T. S. Latharn, AIAA 71-642, June (1971) 